\title{
OPTIMASI KEUNTUNGAN PEMBANGUNAN PERUMAHAN BERDASARKAN JUMLAH RUMAH SETIAP TIPE MENGGUNAKAN PARTICLE SWARM OPTIMIZATION (PSO)
}

\author{
Rozaq Akbar', Dian Eka Ratnanawati ${ }^{2}$, Sutrisno ${ }^{3}$ \\ 1,2,3Fakultas Ilmu Komputer Universitas Brawijaya \\ Email: ${ }^{1}$ rozaqakbar@gmail.com, ${ }^{2}$ dian_ilkom@ub.ac.id, ${ }^{3}$ trisno@ub.ac.id
}

(Naskah masuk: 11 Januari 2017, diterima untuk diterbitkan: 17 Februari 2017)

\begin{abstract}
Abstrak
Tempat tinggal merupakan kebutuhan setiap individu. Selain hal tersebut, laju pertumbuhan penduduk, serta adanya urbanisasi juga mempengaruhi banyaknya permintaan. Perumahan meupakan salah satu jawaban dalam mengatasi permintaan akan perumahan tersebut. Di Indonesia pembangunan perumahan dijalankan oleh Perumnas atau Perusahaan Umum Pembangunan Perumahan Nasional yang selanjutnya akan diteruskan oleh developer atau pengembang. Developer dalam hal ini melakukan berbagai upaya dalam mencapai keuntungan maksimal. Karena itu, dibutuhkan sistem optimasi dalam menangani masalah ini. Penggunaan Particle Swarm Optimization (PSO) akan sangat membantu dalam hal pencarian optimasi keuntungan. Dilihat dari beberapa kasus yang menggunkakan PSO, hasil yang didapatkan adalah penjadwalan sumber daya proyek yang optimal, penyusunan posisi barang dalam peti kemas yang lebih optimal, dan akurasi yang lebih baik dari fungsi keanggotaan. Sesuai dengan pengujian yang dilakukan dengan menggunakan data dari Permata Garden Regency, didapatkan jumlah keuntungan yang lebih optimal dibandingkan dengan keuntungan yang telah dicapai.
\end{abstract}

Kata kunci: kentungan, PSO, perumahan, tempat tinggal, Particle Swarm Optimization, kebutuhan dasar

\begin{abstract}
The residence is the every individual need. In addition, the population growth rate, as well as the urbanization also affect the number of requests. Housing is one of the answers in addressing the demand for such housing. Housing construction in Indonesia run by Perumnas or Perusahaan Umum Pembangunan Perumahan Nasional which would then be forwarded by the private sector which in this case is the developer. In this case, Developer made various efforts to achieve maximum benefit. Therefore, system optimization needed in addressing this issue. Use of Particle Swarm Optimization (PSO) will be very helpful to the search for benefit optimization. Judging from several cases using PSO, the results obtained are scheduling resources optimum project, preparation of the position of the goods in a container which is more optimal, and better accuracy in a membership function. In accordance with the testing conducted using data from the Permata Garden Regency, found the number of benefits that more optimal than the gains that have been achieved.
\end{abstract}

Keywords: benefit, PSO, housing, shelter, Particle Swarm Optimization, basic needs

\section{PENDAHULUAN}

Tempat tinggal merupakan kebutuhan setiap individu. Fungsi dari tempat tinggal itu sendiri adalah untuk keamanan, tempat beristirahat, dan beraktifitas. Tempat tinggal tidak hanya dalam bentuk rumah saja, akan tetapi memiliki beberapa jenis lain, yaitu rumah susun, perumahan, rumah deret, dan apartemen.

Dijelaskan bahwa kebutuhan akan tempat tinggal merupakan kebutuhan dasar, maka permintaan akan tempat tinggal akan semakin besar. Selain hal tersebut, laju pertumbuhan penduduk, serta adanya urbanisasi juga mempengaruhi banyaknya permintaan. Perumahan meupakan salah satu jawaban dalam mengatasi permintaan akan perumahan tersebut.

Pembangunan perumahan tidak hanya dilakukan oleh pihak pemerintah saja, akan tetapi pihak swasta-pun diharapkan ikut serta. Di Indonesia pembangunan perumahan dijalankan oleh Perumnas atau Perusahaan Umum Pembangunan Perumahan Nasional yang dimiliki oleh Badan Usaha Milik Negara atau BUMN. Perumnas didirikan oleh pemerintah sebagai solusi dalam menyediakan perumahan yang layak.

Perumnas menjadi pembuka awal yang selanjutnya akan diteruskan oleh developer atau pengembang. Berdasarkan penelitian yang dilaksanakan oleh REI (Real Estate Indonesia), yang dikerjakan pemerintah sebesar 5 persen. Sedangkan 95 persen dikerjakan oleh developer atau swasta, dimana 80 persennya dilakukan anggota REI (Zuraya, Nidia. 2013). Peluang ini dimanfaatkan dengan baik oleh para developer dalam mengambil keuntungan. Akan tetapi, keuntungan yang didapatkan oleh developer tersebut tidak memenuhi target, karena developer hanya menyesuaikan pembangunan perumahan 
dengan permintaan pasar dan masih belum bisa mengoptimalkan jumlah rumah di lahan yang telah disediakan.

Developer dalam hal ini melakukan berbagai upaya dalam mencapai keuntungan yang maksimal. Mengoptimalkan pemanfaatan lahan yang tersedia sangatlah penting, karena keuntungan maksimal dapat dicapai apabila penggunaan lahan yang ada juga maksimal.

Penggunaan PSO akan sangat membantu dalam hal pencarian optimasi keuntungan. Dikarenakan basic dari PSO itu sendiri adalah sebagai proses optimasi untuk menentukan suatu target keuntungan maksimal yang ingin didapatkan.

Particle Swarm Optimization (PSO) banyak digunakan dalam berbagai tujuan optimasi. Salah satunya terdapat penelitian sebelumnya. Hasil yang didapatkan dari penelitian sebelumnya adalah penjadwalan yang lebih baik, dan memberikan hasil maksimal pada sumber daya proyek. Penelitian ini telah berhasil memberikan solusi optimum untuk penjadwalan sumber daya proyek.

Berdasarkan latar belakang diatas, maka penulis akan merancang system berbasis computer untuk memberikan solusi dalam hal optimasi keuntungan pembangunan perumahan yang berjudul, "OPTIMASI KEUNTUNGAN PEMBANGUNAN PERUMAHAN BERDASARKAN JUMLAH RUMAH SETIAP TIPE MENGGUNAKAN PARTICLE SWARM OPTIMIZATION (PSO)".

\section{DASAR TEORI}

\subsection{Pembangunan Perumahan}

Pembangunan perumahan perlu mendapatkan prioritas, dikarenakan kebutuhan manusia akan sebuah tempat tinggal. Didalam pembangunan perumahan terdapat beberapa tahapan (hasil wawancara: Aldaini, 2016), antara lain:

\section{Penentuan Daerah Perumahan}

Sebuah perusahan developer akan melakukan penentuan untuk memilih daerah mana yang akan dikembangkan serta dijadikan bisnis jual beli rumah. Daerah yang dipilih harus memiliki beberapa kriteria yang ditentukan oleh developer tersebut, sehingga daerah tersebut akan menjadi daerah yang layak dalam pembangunan perumahan, bahkan berprospek tinggi untuk harga jual per unit rumah.

\section{Pembelian Tanah}

Setelah menetukan daerah, maka developer akan melakukan pembelian tanah didaerah tersebut. Pembelian tanah dimaksudkan agar sertifikat tanah yang akan menjadi lahan bangunan dari perumahan tersebut dapat dibentuk sesuai keinginan, yaitu menjadi satu sertifikat induk. Karena tanah memiliki berbagai macam jenis sertifikat, antara lain sertifikat HGB (Hak Guna Bangunan), hak milik, girik, dan lain-lain.

\section{Perancangan Denah serta Desain Rumah}

Dalam hal ini, perancangan denah atau kerangka dilakukan oleh seorang arsitek. Arsitek melakukan pembagian luas tanah, menepatkan sarana dan prasarana disekitar perumahan, serta membuat gambar desain rumah dan rencana anggaran dari pembangunan.

\subsection{Particle Swarm Optimization (PSO)}

Particle Swarm Optimization diinisialisasikan oleh sebuah populasi yang acak dan mencari titik optimal dengan mengupdate tiap hasil pembangkitannya (USU). Dalam konteks optimasi multivariabel ini , kawanan diasumsikan mempunyai ukuran tertentu dengan setiap partikel posisi awalnya yang terletak di suatu lokasi yang acak dalam ruang multidimensional. Setiap partikel diasumsikan memiliki dua karakteristik, yaitu posisi dan kecepatan. Setiap partikel bergerak dalam suatu ruang atau space tertentu dan mengingat posisi terbaik yang pernah dilaluinya atau ditemukannya terhadap sumber makanan atau nilai fungsi objektif tersebut. Setiap partikel menyampaikan informasi atau posisi terbaiknya kepada partikel yang lain dan menyesuaikan posisi dan kecepatan masing-masing berdasarkan informasi yang diterima mengenai posisi yang bagus tersebut.

Parameter PSO adalah sebagai berikut, yaitu jumlah partikel, range, maksimum iterasi, C1 dan $\mathrm{C} 2$, serta Wmin dan Wmax. Untuk proses algoritma Particle Swarm Optimization dijelaskan sebagai berikut (Ria, 2009) :

1. Inisialisasi sekumpulan particle secara acak atau random (setiap particle merepresentasikan solusi yang akan dicoba).

2. Inisialisasi posisi dari setiap particle (Xid) dan kecepatan dari setiap particle (Vid).

3. Hitung nilai fluktuasi dari setiap particle $\mathrm{Fi}$ menggunakan formula fungsi objektif (fitness) dan model yang telah ditentukan sesuai dengan masalah optimasinya.

Fitness $=1 /($ (Tipe $1 *$ harga+Tipe $2 *$ harga + Tipe $3 *$ harg a)+(Tipe1.selisih+Tipe $2 *$ selisih+Tipe $3 *$ selisih $) * C)$ ......(1)

Keterangan :

Tipe $1=$ jumlah rumah dengan tipe 30/72

Tipe2 = jumlah rumah dengan tipe 38/78

Tipe3 = jumlah rumah dengan tipe 45/91

$\mathrm{C}=$ konstanta

Harga = harga jual tiap rumah

Selisih = selisih jumlah rumah dari rekomendasi pakar dan keluaran sistem 
4. Untuk setiap particle, bandingkan nilai fluktuasi Fi dengan nilai terbaik yang telah dicapai Pid (local best)

jika Fi < Pid, maka Pid diganti Fi

5. Untuk setiap particle, bandingkan nilai fluktuasi Fi dengan nilai terbaik yang dicapai dalam Pgd (global best)

jika Fi < Pgd , maka Pgd diganti Fi

6. Berdasarkan persamaaan 4 dan 5 , kecepatan (Vi) dan posisi dari particle $(\mathrm{Xi})$ diubah.

Rumus perubahan kecepatan (Vi) :

$\mathrm{V} \_\mathrm{id}^{\wedge}(\mathrm{t}+1)=\mathrm{w}^{*} \mathrm{v} \_\mathrm{id}{ }^{\wedge} \mathrm{t}+\mathrm{c} \_1 * \operatorname{Rand}()^{*}\left(\mathrm{p} \_\mathrm{id}-\mathrm{x} \_\mathrm{id} \mathrm{d}^{\wedge} \mathrm{t}\right)+$

c_2*Rand ()$^{*}\left(\right.$ p_gd- $\left.\mathrm{x} \_\mathrm{id}{ }^{\wedge} \mathrm{t}\right)$

Rumus perubahan posisi (Xi) :

$\mathrm{x} \_\mathrm{id} \mathrm{d}^{\wedge}(\mathrm{t}+1)=\mathrm{x} \_\mathrm{id} \mathrm{t}^{\mathrm{t}}+\mathrm{V} \_\mathrm{id} \mathrm{d}^{\wedge}(\mathrm{t}+1)$

Rumus $\mathrm{W}$ inersia $(\mathrm{w})$ :

$\mathrm{W}=\mathrm{w} \_\mathrm{max}-\left(\mathrm{w} \_\mathrm{max}-\mathrm{w} \_(\min )\right) / \mathrm{I} \_\mathrm{max} * \mathrm{I}$

Keterangan :

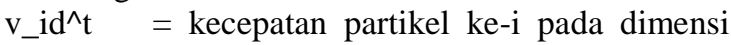
ke-d pada iterasi ke-t

$\mathrm{x} \_\mathrm{id}^{\wedge} \mathrm{t} \quad=$ posisi partikel ke-i pada dimensi ke-d pada iterasi ke-t

$\mathrm{W}=$ bobot inersia

I $\quad=$ Iterasi

I_max = iterasi maksimum

c_1,c_2 = learning rate

$\mathrm{p} \_$(id) $\quad=\mathrm{P}$ best atau posisi terbaik particle pada

$\mathrm{x} \_$id ${ }^{\wedge}$

p_gd $\quad=\mathrm{P}$ global best atau posisi terbaik particle secara keseluruhan

7. Jika telah mencapai kondisi akhir (mencapai nilai iterasi maksimum atau perulangan telah mencapai nilai optimum) maka perulangan akan berhenti dan nilai optimumnya didapatkan namun jika belum maka diulangi pada nomor 3 .

\subsection{Random Injection}

Pada ruang pencarian yang tidak terlalu besar, sering dijumpai pencapaian konvergensi dini. Hal ini disebabkan karena partikel lebih cepat menemukan posisi terbaik global dalam ruang pencarian yang kecil dan disebabkan kurangnya diversitas setelah melewati beberapa generasi (Mahmudy, 2014). Untuk mengatasi hal tersebut dan membuat partikel lebih teliti atau bertahap dalam melakukakn eksploitasi lokal dan eksplorasi global, maka diterapkan sistem random injection. Random injection dilakukan dengan menginisialisasi kembali posisi $\mathrm{n}$ partikel setiap $\mathrm{g}$ interval iterasi. Penentuan $\mathrm{n}$ dan $\mathrm{g}$ yang sesuai dilakukan berdasrkan beberapa percobaan sebelumnya pada sistem PSO.

\section{METODOLOGI PENELITIAN}

Dalam bab ini akan dibahas mengenai tahapan yang akan dilakukan dalam penelitian. Tahapan yang ada ditunjukkan dalam gambar dibawah ini.

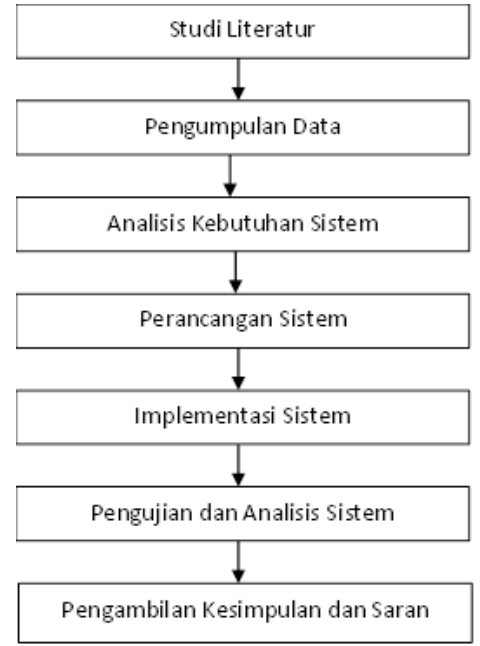

Gambar 3.1 Tahapan Penelitian

\section{PERANCANGAN SISTEM}

Pada bab ini akan dijelaskan mengenai hal-hal yang berhubungan dengan perancangan sistem, dimulai dari alir perancangan sistem, perancangan antarmuka pengguna, perancangan pengujian, serta analisis sistem.

\subsection{Alir Perancangan Sistem}

Pada tahap alir perancangan sistem, terdapat penjelasan mengenai bagaimana proses yang terjadi didalam system menggunakan algoritma particle swarm optimization (PSO), yang ditunjukkan oleh gambar 4.1 berikut ini.

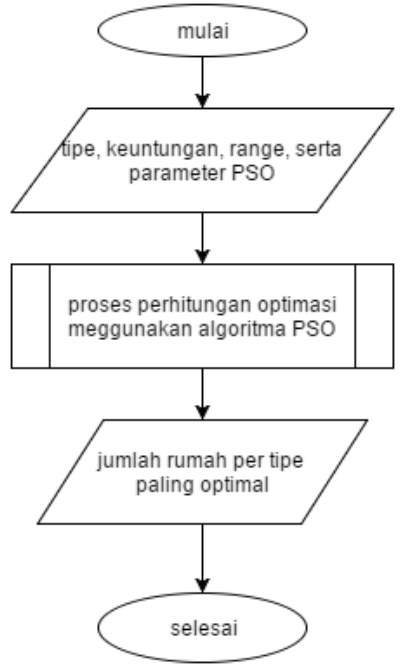

Gambar 4.1 Diagram Alir Perancangan Sistem

\subsection{Alir Perancangan Sistem Perhitungan Algoritma Particle Swarm Optimization (PSO)}

Proses perhitungan menggunakan algoritma PSO untuk menghasilkan output terbaik. Pada Gambar 4.2 dibawah ini ditunjukkan bagaimana alir algoritma Particle Swarm Optimization (PSO) untuk optimasi keuntungan pembangunan perumahan berdasarkan jumlah rumah setiap tipe 
menggunakan Particle Swarm Optimization (PSO). Dimulai dari memasukkan tipe rumah yang akan dibangun, kemudian memasukkan keuntungan yang didapatkan dari setiap satu tipe rumah yang akan dijual, memasukkan range dari setiap tipe rumah yang akan dibangun. Selain itu, memasukkan masukan berupa parameter dari PSO tersebut. Didalam gambar dijelaskan bahwa setelah proses memasukkan inputan akan dilakukan proses inisialisasi partikel. Dalam algoritma Particle Swarm Optimization (PSO) dilakukan pula perhitungan fungsi obyektif. Setelah proses tersebut berjalan dilakukan pencarian Pbest dan Gbest yang dilanjutkan dengan memperbarui posisi Xid dan kecepatan partikel Vid. Kemudian dilakukan pengulangan sampai mencapai iterasi maksimal. Hal ini dilakukan untuk menghasilkan jumlah rumah setiap tipe yang akan digunakan untuk mendapatkan keuntungan maksimal. Proses-proses tersebut dijelaskan dalam diagram alir dibawah ini

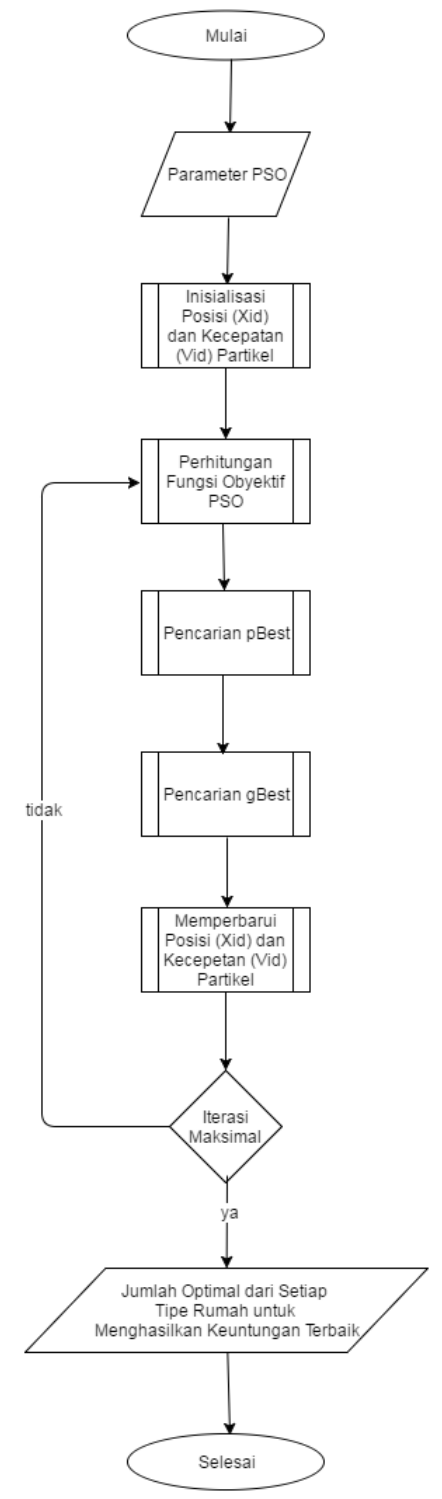

Gambar 4.2 Diagram Alir Algoritma Particle Swarm Optimization (PSO)

\section{PENGUJIAN DAN ANALISIS}

\subsection{Pengujian dan Analisis Jumlah Partikel}

Pengujian banyaknya jumlah partikel digunakan untuk menentukan jumlah partikel yang digunakan untuk untuk isian default sistem, sehingga pengguna tidak perlu mengisikan parameter-parameter PSO, dan sudah memberikan solusi yang terbaik. Pengujian ini menggunakan beberapa ukuran swarmsize yang berbeda dengan kelipatan 2. Pengujian dilakukan sebanyak 5 kali untuk setiap jumlah partikel.

\begin{tabular}{|c|c|c|}
\hline problem dimension & & 7 \\
\hline $\mathrm{c} 1$ & : & 2 \\
\hline c2 & : & 1 \\
\hline Wmin & : & 0 \\
\hline Wmax & : & 1 \\
\hline r1 & : & 0.163251 \\
\hline $\mathrm{r} 2$ & : & 0.183259 \\
\hline $\mathrm{V}(1,0)$ & & 0 \\
\hline max iteration & : & 50 \\
\hline
\end{tabular}

Tabel 5.1 Rata-Rata Fitness Dari Hasil Pengujian Jumlah Partikel

\begin{tabular}{|c|c|}
\hline $\begin{array}{c}\text { Jumlah partikel } \\
\text { (Swarmsize) }\end{array}$ & Rata-rata fitness \\
\hline 5 & $3.34 \mathrm{E}-11$ \\
\hline 7 & $3.00 \mathrm{E}-11$ \\
\hline 9 & $3.30 \mathrm{E}-11$ \\
\hline 11 & $3.00 \mathrm{E}-11$ \\
\hline 13 & $2.81 \mathrm{E}-11$ \\
\hline 15 & $3.18 \mathrm{E}-11$ \\
\hline
\end{tabular}

Tabel 5.1 menunjukkan bahwa nilai fitness tidak selalu semakin membaik seiring dengan bertambahnya jumlah partikel.

\subsection{Pengujian dan Analisis Jumlah Maksimum Iterasi}

Pengujian terhadap banyaknya jumlah maksimum iterasi untuk mengetahui maksimum iterasi yang optimal dan dapat menghasilkan solusi yang lebih baik. Pada pengujian jumlah partikel telah didapatkan jumlah partikel yang tidak terlalu banyak, akan tetapi memliki hasil yang bagus yaitu 13. Nilai parameter tersebut akan digunakan dalam pengujian ini. Pengujian ini menggunakan beberapa ukuran maksimum iterasi yang berbeda dengan kelipatan 15. Pengujian dilakukan sebanyak 5 kali untuk masing-masing ketentuan maksimum iterasi.

$\begin{array}{lll}\text { swarm size } & : & 13 \\ \text { problem dimension } & : & 7 \\ \text { c1 } & : & 2 \\ \text { c2 } & : & 1 \\ \text { Wmin } & : & 0 \\ \text { Wmax } & : & 1 \\ \text { r1 } & : & 0.163251\end{array}$


r2

$\mathrm{V}(1,0)$

$: \quad 0.183259$

Tabel 5.2 Rata-Rata Fitness Dari Hasil Pengujian Maksimum Iterasi

\begin{tabular}{|c|r|}
\hline$t \max$ & Rata-rata fitness \\
\hline 20 & $3.32 \mathrm{E}-11$ \\
\hline 35 & $3.11 \mathrm{E}-11$ \\
\hline 50 & $3.02 \mathrm{E}-11$ \\
\hline 65 & $2.95 \mathrm{E}-11$ \\
\hline 80 & $2.98 \mathrm{E}-11$ \\
\hline
\end{tabular}

Berdasarkan Tabel 5.2 menunjukkan bahwa nilai fitness tidak selalu semakin membaik seiring dengan bertambahnya jumlah iterasi.

\subsection{Hasil Optimasi}

Dimana terdapat hasil dari setiap iterasi beserta fitness dari setiap jumlah tipe rumah. Tampilan halaman hasil optimasi ditunjukkan dalam Gambar 5.3, 5.4, dan 5.5 berikut:

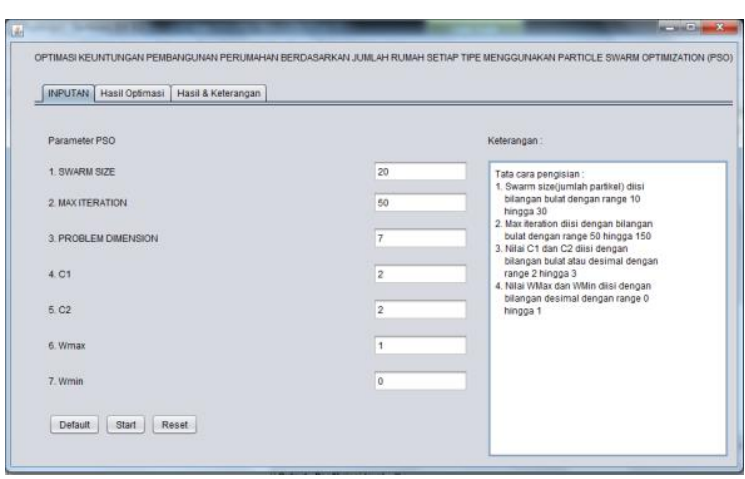

Gambar 5.3 Halaman Tampilan Awal

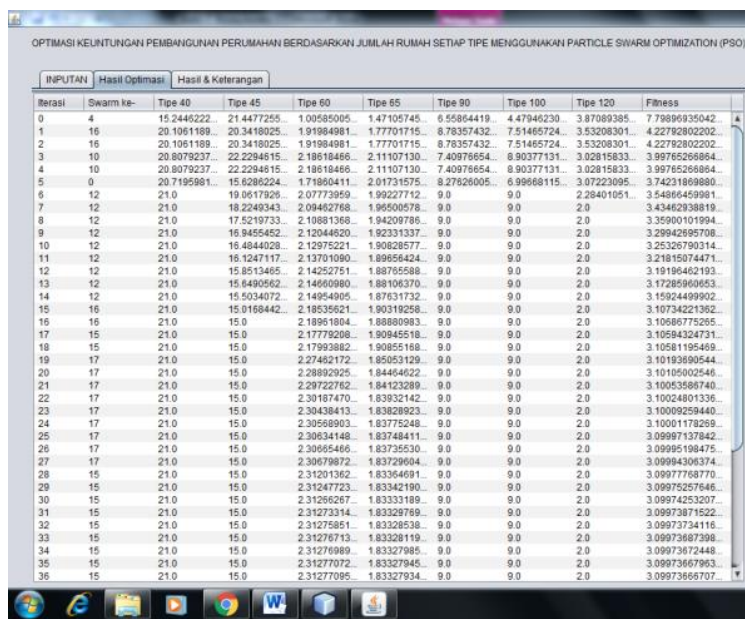

Gambar 5.4 Halaman Hasil Optimasi

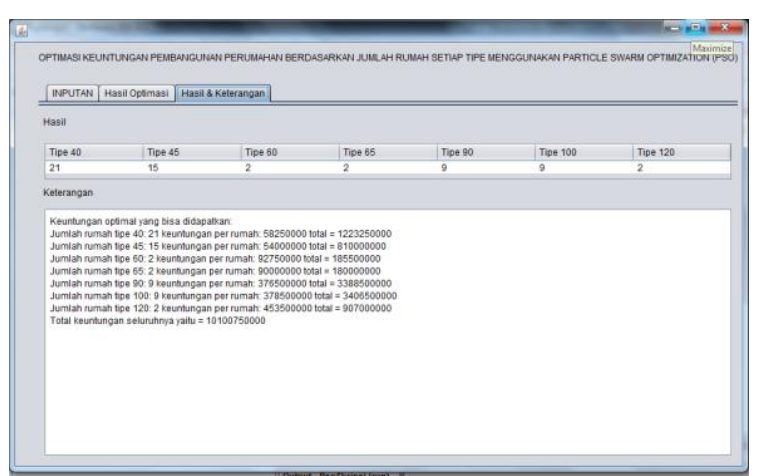

Gambar 5.5 Halaman Hasil Dan Keterangan

Tabel 5.3 Hasil Optimal Sistem

\begin{tabular}{|l|l|l|l|l|l|l|l|l|l|}
\hline ite & swa & tip & ti & ti & ti & ti & ti & ti & \\
ra & rm & e & pe & pe & e & pe & pe & pe & Fitn \\
si & ke- & 40 & 4 & 6 & 6 & 9 & 0 & 2 & ess \\
& & & 5 & 0 & 5 & 0 & 0 & 0 & \\
\hline 64 & 9 & 21 & 1 & 3 & 2 & 9 & 9 & 4 & $\begin{array}{l}3.0 \\
1 E- \\
11\end{array}$ \\
\hline
\end{tabular}

Berdasarkan Tabel 5.3 dapat dihitung berapa jumlah keuntungan yang didapatkan, kemudian dibandingkan dengan hasil dari pakar adalah sebagai berikut.

Tabel 5.4 Hasil Perhitungan Keuntungan oleh

Sistem dan Hasil Perhitungan Keuntungan oleh Pakar

\begin{tabular}{|c|c|c|c|c|}
\hline \multirow[b]{2}{*}{$\begin{array}{l}\text { Tipe } \\
\mathrm{Ru} \\
\mathrm{mah}\end{array}$} & \multicolumn{2}{|l|}{ Sistem } & \multicolumn{2}{|l|}{ Pakar } \\
\hline & $\begin{array}{l}\text { Jumlah } \\
\text { Rumah }\end{array}$ & $\begin{array}{l}\text { Keuntunga } \\
\mathrm{n}\end{array}$ & $\begin{array}{l}\text { Jumla } \\
\mathrm{h} \\
\text { Ruma } \\
\mathrm{h}\end{array}$ & $\begin{array}{l}\text { Keuntung } \\
\text { an }\end{array}$ \\
\hline $\begin{array}{l}\text { tipe } \\
40\end{array}$ & 21 & $\begin{array}{l}\text { Rp.1.223.2 } \\
50.000,-\end{array}$ & 16 & $\begin{array}{l}\text { Rp.932.00 } \\
0.000,-\end{array}$ \\
\hline $\begin{array}{l}\text { tipe } \\
45\end{array}$ & 15 & $\begin{array}{l}\text { Rp.810.000 } \\
.000,-\end{array}$ & 21 & $\begin{array}{l}\text { Rp.1.134. } \\
000.000,-\end{array}$ \\
\hline $\begin{array}{l}\text { tipe } \\
60\end{array}$ & 3 & $\begin{array}{l}\text { Rp. } 278.250 \\
.000,-\end{array}$ & 1 & $\begin{array}{l}\text { Rp.92.750 } \\
.000,-\end{array}$ \\
\hline $\begin{array}{l}\text { tipe } \\
65\end{array}$ & 2 & $\begin{array}{l}\text { Rp. } 180.000 \\
.000,-\end{array}$ & 1 & $\begin{array}{l}\text { Rp. } 90.000 \\
.000,-\end{array}$ \\
\hline $\begin{array}{l}\text { tipe } \\
90\end{array}$ & 9 & $\begin{array}{l}\text { Rp.3.388.5 } \\
00.000,-\end{array}$ & 5 & $\begin{array}{l}\text { Rp.1.882. } \\
500.000,-\end{array}$ \\
\hline $\begin{array}{l}\text { tipe } \\
100\end{array}$ & 9 & $\begin{array}{l}\text { Rp.3.406.5 } \\
00.000,-\end{array}$ & 5 & $\begin{array}{l}\text { Rp.1.892. } \\
500.000,-\end{array}$ \\
\hline $\begin{array}{l}\text { tipe } \\
120\end{array}$ & 4 & $\begin{array}{l}\text { Rp.1.814.0 } \\
00.000,-\end{array}$ & 3 & $\begin{array}{l}\text { Rp.1.360. } \\
500.000,-\end{array}$ \\
\hline $\begin{array}{l}\text { Tota } \\
1\end{array}$ & 63 & $\begin{array}{l}\text { Rp.11.100. } \\
500.000,-\end{array}$ & 52 & $\begin{array}{l}\text { Rp.4.131. } \\
250.000,-\end{array}$ \\
\hline
\end{tabular}

Dari perhitungan di atas dapat dihitung perbandingan keuntungan antara data yang diberikan oleh hasil wawancara dan data hasil optimasi menggunakan algoritma PSO adalah $\begin{array}{llll}11.100 .500 .000 & - & 4.131 .250 .000=\end{array}$ Rp.6.969.250.000,- 


\section{KESIMPULAN DAN SARAN}

\subsection{Kesimpulan}

Berdasarkan hasil penelitian dan pengujian yang telah dilakukan, maka dapat diambil kesimpulan sebagai berikut.

1. Proses PSO dapat diterapkan pada masalah perhitungan optimasi pembangunan perumahan. Dengan mendefinisikan sejumlah partikel sebagai solusi dalam setiap ruang pencarian secara random. Kemudian pada proses pencarian solusi terbaik, dihitung kecepatan perpindahan partikel dalam ruang pencarian dan posisi partikel setelah perpindahan. Posisi partikel inilah yang merepresentasikan jumlah rumah yang akan dibangun untuk setiap tipe. Setiap perpindahan posisi, partikel akan mengevaluasi dan membandingkan posisi yang pernah dilalui dan diambil menjadi posisi terbaik individu. Selanjutnya solusi terbaik dipilih dari posisi terbaik global yang diambil dengan cara membandingkan seluruh posisi terbaik individu.

2. Penentuan nilai parameter yang tepat sangat penting untuk mendapatkan hasil optimasi keuntungan. Didapatkan pada pengujianpengujian diatas bahwa parameter terbaik yang dapat digunakan pada kasus ini adalah jumlah partikel sebanyak 13, sedangkan untuk iterasi maksimal sebanyak 65 .

3. Didapatkan pula perbedaan jumlah rumah setiap tipe antara pakar dan sistem adalah sebanyak 11.

\subsection{Saran}

1. Penelitian ini dilakukan pada cluster Permata Garden Regency, diharapkan penelitian dapat diterapkan dalam optimasi keuntungan untuk kasus lain.

2. Dalam parameter PSO tidak terdapat perhitungan dalam menentukan parameter tersebut. Diharapkan dengan lebih banyak percobaan mengenai penentuan parameter, akan menghasilkan keuntungan yang lebih optimal.

\section{DAFTAR PUSTAKA}

ASHRI F., PUTRI Y. E., \& INDRYANI R. 2011. Optimasi Jumlah Unit Rumah Tiap Tipe Pada Perumahan Green Hill Gresik. Surabaya.

BISILISIN F. Y., HERDIYENI Y., \& SILALAHI B. P. 2014. Optimasi K-Means Clustering Menggunakan Particle Swarm Optimization pada Sistem Identifikasi Tumbuhan Obat Berbasis Citra. Bogor.

BUMN. Tentang Perusahaan. Tersedia di <http://bumn.go.id/perumnas/halaman/41/t entang-perusahaan.html> [Diakses

Februari 2016]

ERNY. 2013. Optimasi Pola Penyusunan Barang dalam Peti Kemas Menggunakan Algoritma Particle Swarm Optimization. Makassar.

KENNEDY J. \& EBERHART R. 1995. Particle Swarm Optimization. International Conference on Neural Networks, vol. 4, Nov 1995, 19421948. New Jersey.

MAHMUDY, W. F. (2014). Optimasi penjadwalan two-stage assembly flowshop menggunakan algoritma genetika yang dimodifikasi. Konferensi Nasional Sistem Informasi (KNSI), pp. 478-483.

MAHMUDY, W. F. (2014). Optimasi Part Type Selection And Machine Loading Problems Pada FMS Menggunakan Metode Particle Swarm Optimization. Konferensi Nasional Sistem Informasi 2014. Makassar.

MANSUR, PRAHASTO T., \& FARIKHIN. 2014. Particle Swarm Optimization Untuk Sistem Informasi Penjadwalan Resource Di Perguruan Tinggi. Semarang.

NADIASA M. 2012. Optimalisasi Pembangunan Perumahan Grand Renon Prime Residence. Denpasar.

NIDIA Z. 2013. REI: Swasta Lebih Berperan Dalam Sektor Perumahan. Jakarta. Tersedia di <http://www.republika.co.id/berita/ekono mi/bisnis/13/11/20/mwjupo-rei swastalebih-berperan-dalam-sektor-perumahan> [Diakses 7Februari 2016]

RATNA P. P. S., DEWI C., INDRIATI. 2013. IMPLEMENTASI ALGORITMA PARTICLE SWARM OPTIMIZATION UNTUK OPTIMASI FUNGSI KEANGGOTAAN PADA KONDISI PENDERITA PENYAKIT HEPATITIS. Malang.

REAL ESTATE INDONESIA. 2015. Bangun Satu Juta Rumah, REI Beri 14 Syarat ke Pemerintah. Jakarta. Tersedia di <http://www.rei.or.id/berita.php> [Diakses 7 Februari 2016]

TUEGEH M., SOEPRIJANTO A., \& HERY M. P. 2009. Optimal Generator Scheduling Based On Particle Swarm Optimization. Seminar Nasional Informatika 2009 (semnasIF 2009). Yogyakarta.

TUEGEH M., SOEPRIJANTO A., \& HERY M. P. (2009). Modified Improved Particle Swarm Optimization For Optimal Generator Scheduling. Seminar Nasional Aplikasi Teknologi Informasi 2009 (SNATI 2009). ISSN: 1907-5022. Yogyakarta.

UNDANG-UNDANG REPUBLIK INDONESIA NOMOR 4 TAHUN 1992. 1992. Tersedia 
di

<http://www.sjdih.depkeu.go.id/fulltext/19 92/4TAHUN 1992UUPenj.htm $>$ [Diakses 7 Februari 2016]

WATI D. A. R. \& ROCHMAN Y. A. (2013). Model Penjadwalan Matakuliah Secara Otomatis Berbasis Algoritma Particle Swarm Optimization (PSO). Yogyakarta.

ZERDA E. R. 2009. Analisis dan Penerapan Algoritma Particle Swarm Optimization ( $P S O$ ) pada Optimasi Penjadwalan Sumber Daya Proyek. Bandung. 